\title{
Outcomes of Late Implantation in Usher Syndrome Patients
}

\author{
Ana Cristina H. Hoshino ${ }^{1}$ Agustina Echegoyen ${ }^{1}$ Maria Valéria Schmidt Goffi-Gomez ${ }^{2}$ \\ Robinson Koji Tsuji ${ }^{3}$ Ricardo Ferreira Bento ${ }^{3}$ \\ ${ }^{1}$ Department of Otolaryngology, Hospital das Clínicas, São Paulo, \\ SP, Brazil \\ ${ }^{2}$ Cochlear Implant Group, School of Medicine, Hospital das Clínicas, \\ Universidade de São Paulo, São Paulo, SP, Brazil \\ ${ }^{3}$ Department of Otolaryngology, Universidade de São Paulo, \\ São Paulo, SP, Brazil \\ Int Arch Otorhinolaryngol 2017;21:140-143. \\ Address for correspondence Ana Cristina H. Hoshino, PhD, \\ Department of Otorrinolaringologia, Hospital das Clínicas, R. Vigário \\ Albernaz, 843/74 São Paulo 04134-021, Brazil \\ (e-mail: choshino@uol.com.br).
}

\begin{abstract}
Keywords

- usher syndromes

- cochlear implant

- delayed diagnosis

- quality of life

Introduction Usher syndrome (US) is an autosomal recessive disorder characterized by hearing loss and progressive visual impairment. Some deaf Usher syndrome patients learn to communicate using sign language. During adolescence, as they start losing vision, they are usually referred to cochlear implantation as a salvage for their new condition. Is a late implantation beneficial to these children?

Objective The objective of this study is to describe the outcomes of US patients who received cochlear implants at a later age.

Methods This is a retrospective study of ten patients diagnosed with US1. We collected pure-tone thresholds and speech perception tests from pre and one-year post implant.

Results Average age at implantation was 18.9 years (5-49). Aided average thresholds were $103 \mathrm{~dB} \mathrm{HL}$ and $35 \mathrm{~dB} \mathrm{HL}$ pre and one-year post implant, respectively. Speech perception was only possible to be measured in four patients preoperatively, who scored 13.3; 26.67; 46\% vowels and 56\% 4-choice. All patients except one had some kind of communication. Two were bilingual. After one year of using the device, seven patients were able to perform the speech tests (from four-choice to close set sentences) and three patients abandoned the use of the implant.

Conclusion We observed that detection of sounds can be achieved with late implantation, but speech recognition is only possible in patients with previous hearing stimulation, since it depends on the development of hearing skills and the maturation of the auditory pathways.
\end{abstract}

\section{Introduction}

The Usher syndrome is an autosomal recessive disease characterized by varying degrees of sensorineural hearing loss and progressive visual impairment, caused by retinitis pigmentosa (RP). ${ }^{1}$

The syndrome's incidence is estimated as $3-6 / 100.000$ persons in the general population. Among the deaf popu-

received

November 9, 2015

accepted

March 20, 2016

published online

May 4, 2016 10.1055/s-0036-1583306. ISSN 1809-9777. lation, the prevalence of the syndrome is 3 to $6 \%$. It is the most frequent cause of adult blindness and deafness. Studies underestimate the true prevalence of the disease due to lack of early diagnosis or for being misdiagnosed. The average age at diagnosis is 10 years and some children are implanted before vision loss and even before the diagnosis of Usher's disease. ${ }^{1}$

Copyright $\odot 2017$ by Thieme-Revinter

Publicações Ltda, Rio de Janeiro, Brazil
License terms

(ब) (1) $\Theta \circledast$ 
Three distinct subtypes of the syndrome have been described. Usher Type I (USHI) is characterized by profound sensorineural hearing loss at birth or during the first year of life, abnormal vestibular function, and delayed motor development. Children with Usher type II (USHII) have hearing loss from birth moderate to severe and normal vestibular function. Affected children with Usher type III (USHIII) are usually born with normal hearing and undergo progressive hearing loss. Their vestibular function may be affected. The vision loss is gradual and usually begins in adolescence or adulthood. ${ }^{2}$ The severity of hearing loss and blindness is higher in Usher syndrome type I.

Several studies of patients with Usher syndrome concluded that cochlear implant $(\mathrm{CI})$ is an effective treatment for such patients, since there is a deterioration of a duplicate sensory. Benefits vary from a better quality of life, observed in questionnaires, ${ }^{3}$ to superior performance in oral communication. ${ }^{2,4-6}$ This variability of the results is seen as being dependent on factors such as age of implantation, duration of deafness, and type communication prior to implantation. ${ }^{6,7}$

Families have sought the solution for children with Usher syndrome who did not have the opportunity to receive cochlear implants in early childhood, since the visual loss is progressive, starting in adolescence.

We seek to investigate whether late implant patients presenting Usher syndrome type I with pre-lingual hearing loss can benefit the cochlear implant.

\section{Method}

Among the 1.350 patients implanted in our service, 13 (0.9\%) have Usher syndrome, 10 are USHI, and three are USHII. We conducted a retrospective study of data collection. We selected all patients with USHI and excluded patients with USHII plus those who had not been yet implanted. We collected patients' age at the time of surgery, type of communication before and after surgery, hearing thresholds (PTA) pre (with hearing aid) and post implant (1 year of $\mathrm{CI}$ use), and the performance of speech perception pre and post implant. The protocol used to conduct the testing was according to Goffi Gomez et al. ${ }^{8}$

The subjects were classified according to mode of communication. In the case of bilinguals, we set up the first way of communication as the mother language or that of greater fluency.

\section{Results}

We selected 10 patients implanted ( 7 men, 3 women) diagnosed with USHI. The average age for implantation was 18.9 years (5-49). - Table 1 describes the summary of the characteristics of each patient.

Average pre auditory threshold (PTA HA) was $103 \mathrm{~dB}$ HL (-Fig. 1). It was possible to measure speech perception in four patients preoperatively $(1,2,4$, and 6$)$, who could only detect speech. Other patients failed to perform the speech perception tests. All patients except one had some kind of effective communication. Two were bilingual (-Table 2).

One year after the implantation, the average auditory threshold (PTA CI) was $35 \mathrm{~dB}$ (-Fig. 1). Only three patients improved their performance in speech perception to $40 \%, 30 \%$, and $10 \%$ for recognition of sentences in closed set, respectively (1, 2 and 3); five patients had only speech detection, and two were not able to carry out tests ( - Table 2 ). Three patients abandoned the use of $\mathrm{CI}(8,9$, and 10$)$.

\section{Discussion}

For proper indication and to establish a prognosis of the cochlear implantation beyond the knowledge of the etiology of deafness patients, it is important to survey the use of hearing aids and residual hearing that allows us to infer the development of the auditory pathway. ${ }^{9}$ This will allow us to manage the expectations of the patient and family after cochlear implantation. Several factors can influence the outcome of cochlear implants as age of occurrence / diagnosis

Table 1 Summary of the characteristics of the 10 patients with implanted Usher syndrome

\begin{tabular}{|l|l|l|l|l|l|l|l|l|}
\hline ID & $\begin{array}{l}\text { HA use } \\
\text { (years) }\end{array}$ & $\begin{array}{l}\text { Diagnosis } \\
\text { age (years) }\end{array}$ & $\begin{array}{l}\text { Implanted } \\
\text { age (years) }\end{array}$ & Side & School & Visual & Cl model & $\begin{array}{l}\text { Speech } \\
\text { strategy }\end{array}$ \\
\hline 1 & 11 & 1 & 13 & $R$ & Mainstream & RP & Cochlear Nucleus 24M/K & ACE \\
\hline 2 & 7 & 1 & 9 & R & Mainstream & RP & Cochlear Nucleus 24M/K & ACE \\
\hline 3 & 10 & 1 & 12 & R & Mainstream & RP & Cochlear Nucleus Freedom & ACE \\
\hline 4 & 22 & 1 & 23 & L & Mainstream & RP & Cochlear Nucleus Freedom & ACE \\
\hline 5 & 6 & 2 & 18 & L & Special & RP & Neurelec Digisonic SP & MPIS \\
\hline 6 & 27 & 2 & 29 & R & Special & RP & Cochlear Nucleus 24M/K & ACE \\
\hline 7 & 12 & 2 & 49 & R & Special & RP & Medel Sonata & CIS \\
\hline 8 & 1 & 1 & 5 & L & Special & RP & Cochlear Nucleus 24M/K & ACE \\
\hline 9 & 5 & 1 & 16 & L & Special & RP & Cochlear Nucleus 24M/K & ACE \\
\hline 10 & 13 & 2 & 15 & L & Special & RP & AB HiRes 90k & HIRESS \\
\hline
\end{tabular}

Abbreviations: $\mathrm{Cl}$, cochlear implants; $\mathrm{HA}$, individual sound amplification device; RP, retinitis pigmentosa. 


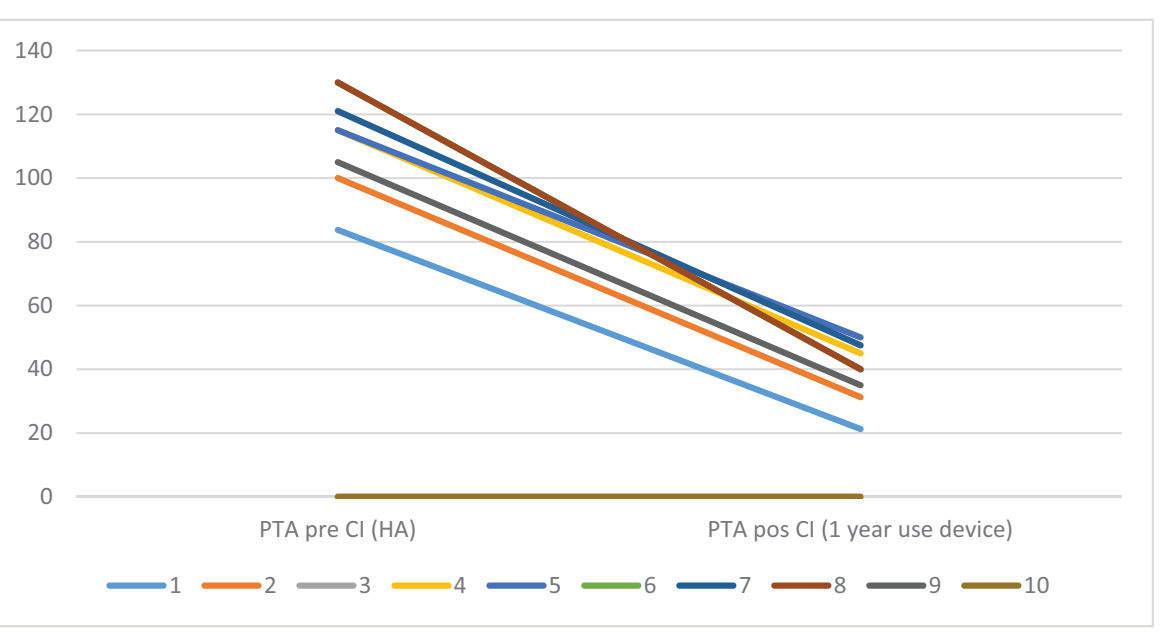

Fig. 1 Results of average hearing thresholds pre and post one year of use device.

of hearing loss (pre versus post-lingual) age at implant, residual hearing, systematic use of hearing aids, communication mode, support from family, and educational environment, as well as rehabilitation and personal motivation to join to the world of sound and learn to listen.

Indeed, studies on Usher syndrome reported outcomes of patients implanted with different ages and conclude that patients implanted late have good sound detection thresholds, $2,4,6$ but the worst speech perception performance.

The fact that Usher syndrome patients are deprived of another sensory pathway does not necessarily mean that the patients will benefit from this type of rehabilitation. The clinical team should evaluate patients with Usher syndrome carefully and discuss the prognosis both in team and with the family.

The history of the systematic use of hearing aids, residual hearing, and the mode of communication allow us to infer the value that the patient places on oral communication and listening in their life. They may not develop auditory cortical area and symbolic meaning of sounds. Patients who had no prior central auditory skills because they never had access to sounds when implanted can hardly adapt, leading to treatment failure. ${ }^{10}$ The development of oral language skills from birth is essential to the patient subsequently acquire the new language sound of the cochlear implant. They need to use systematically bilateral hearing aids (even with little benefit) to keep the peripheral and central pathways as preserved as possible and learning one or more languages from birth. ${ }^{11,12}$ It is possible to the baby with congenital deafness to acquire the natural neurobiological development when the auditory stimulation is restored before 3.5 years of age (Sharma et al., 2009), ${ }^{13}$ on the other hand, patients implanted late show changes in the number of projections or synaptic density at various levels of the auditory pathway. ${ }^{10-14}$

Table 2 Description of communication modes and results of speech perception of 10 patients with Usher syndrome type I

\begin{tabular}{|l|l|l|l|l|l|l|l|}
\hline Pre Cl & \multicolumn{4}{l|}{ Pos Cl (1 year of use device) } \\
\hline Subjects & $\begin{array}{l}\text { Communication } \\
\text { mode }\end{array}$ & PTA HA & $\begin{array}{l}\text { Speech } \\
\text { perception }\end{array}$ & $\begin{array}{l}\text { Age } \\
\text { at Cl }\end{array}$ & $\begin{array}{l}\text { Communication } \\
\text { mode }\end{array}$ & PTA CI & Speech perception \\
\hline $\mathbf{1}$ & Sign language/ Oral & 83.75 & $13,3 \%$ vowels & 13 & Sign language/ Oral & 21.25 & $40 \%$ closed set \\
\hline $\mathbf{2}$ & Oral/ Sign language & 100 & $26,67 \%$ vowels & 9 & Oral/ Sign language & 31.25 & $30 \%$ closed set \\
\hline $\mathbf{3}$ & Sign language & 130 & NT & 12 & Sign language & 40 & $10 \%$ closed set \\
\hline $\mathbf{4}$ & Oral & 115 & $46 \%$ vowels & 23 & Oral/ Sign language & 45 & $53 \%$ vowels \\
\hline $\mathbf{5}$ & Sign language & 115 & NT & 18 & Sign language & 50 & $20 \%$ vowels \\
\hline $\mathbf{6}$ & Oral & 130 & $56 \% 4$ choice & 29 & Oral & 40 & $15 \%$ vowels \\
\hline $\mathbf{7}$ & Oral & 121 & NT & 49 & Oral & 47.5 & $58 \% 4$ choice \\
\hline $\mathbf{8}$ & Sign language & 130 & NT & 5 & Sign language & 40 & NU \\
\hline $\mathbf{9}$ & Sign language & 105 & NT & 16 & Sign language & 35 & NU \\
\hline $\mathbf{1 0}$ & No language & 123.75 & NT & 15 & Sign language & 31.25 & $60 \%$ vowels \\
\hline
\end{tabular}

Abbreviations: $\mathrm{Cl}$, cochlear implants; $\mathrm{HA}$, individual sound amplification device; $\mathrm{NT}$, not tested; NU, non user $\mathrm{Cl}$ patient; $\mathrm{PTA} \mathrm{Cl}$, pure tone threshold of cochlear implant; PTA HA, pure tone threshold of hearing aid. (no access to speech sounds even with the use of hearing aids). 
Detecting the sounds achieved by the majority of our patients show that cochlear implants can provide access to sounds (peripheral input), however, when the implant is delayed, maybe, there are not enough central connections between the auditory area and the association areas. That means that detection is not enough for these people to give meaning to the sounds that they hear and may not be able to achieve the representation of the sounds. Another important factor is the inadequate expectations of the patient and families. Many teens already fluent in sign language also are disappointed with the $\mathrm{CI}$ because they might have expected something that had not happened, because the family might have imposed it or that his expectation was beyond that treatment could offer. The cochlear implant teams based on their own experience should judge each case individually to ensure realistic expectations of the outcome. This suggests that traditional measures of speech perception may not be sufficient to accurately reflect the real benefit of $\mathrm{Cl}$ and alternative assessment tools, including educational, social and psychological areas are needed. ${ }^{15-19}$

\section{Conclusion}

Patients with Usher syndrome who were lately implanted have good hearing thresholds, but speech recognition and use of the device will depend mainly of previous stimulation, since they are directly related to the development of the auditory pathway and the central auditory skills.

\section{References}

1 Bronya JB. Keats, FACMG and Jennifer Lentz. Usher Syndrome Type I. GeneReviews ${ }^{\circledR}$ [Internet]. Initial Posting: December 10, 1999; Last Update: June 20, 2013. http://www.ncbi.nlm.nih.gov/books/ NBK1265/ accessed in October,2015

2 Loundon N, Marlin S, Busquet D, et al. Usher syndrome and cochlear implantation. Otol Neurotol 2003;24(2):216-221

3 Damen GW, Pennings RJ, Snik AF, Mylanus EA. Quality of life and cochlear implantation in Usher syndrome type I. Laryngoscope 2006;116(5):723-728

4 Jatana KR, Thomas D, Weber L, Mets MB, Silverman JB, Young NM. Usher syndrome: characteristics and outcomes of pediatric cochlear implant recipients. Otol Neurotol 2013;34(3):484-489
5 Henricson C, Wass M, Lidestam B, Möller C, Lyxell B. Cognitive skills in children with Usher syndrome type 1 and cochlear implants. Int J Pediatr Otorhinolaryngol 2012;76(10): $1449-1457$

6 Liu XZ, Angeli SI, Rajput K, et al. Cochlear implantation in individuals with Usher type 1 syndrome. Int J Pediatr Otorhinolaryngol 2008;72(6):841-847

7 Pietola L, Aarnisalo AA, Abdel-Rahman A, et al. Speech recognition and communication outcomes with cochlear implantation in Usher syndrome type 3. Otol Neurotol 2011;33(1):38-41

8 Goffi-Gomez MVS, Guedes MC, Sant'anna SBG, et al. Critérios de seleção e avaliação médica e audiológico dos candidatos ao implante coclear. Protocolo HCFMUSP. Arquivos Int Otorrinolaringol. 2004;8(4):303-323

9 Lazard DS, Vincent C, Venail F, et al. Pre-, per- and postoperative factors affecting performance of postlinguistically deaf adults using cochlear implants: a new conceptual model over time. PLoS ONE 2012b7(11):e48739

10 Lee HJ, Giraud AL, Kang E, et al. Cortical activity at rest predicts cochlear implantation outcome. Cereb Cortex 2007;17(4): 909-917

11 Lazard DS, Giraud AL, Gnansia D, Meyer B, Sterkers O. Understanding the deafened brain: implications for cochlear implant rehabilitation. Eur Ann Otorhinolaryngol Head Neck Dis 2012a129(2): 98-103

12 Butler BE, Lomber SG. Functional and structural changes throughout the auditory system following congenital and early-onset deafness: implications for hearing restoration. Front Syst Neurosci 2013;7:92

13 Sharma A, Nash AA, Dorman M. Cortical development, plasticity and re-organization in children with cochlear implants. J Commun Disord 2009;42(4):272-279

14 Campbell J, Sharma A. Cross-modal re-organization in adults with early stage hearing loss. PLoS ONE 2014;9(2):e90594

15 Broomfield SJ, Bruce IA, Henderson L, Ramsden RT, Green KM. Cochlear implantation in children with syndromic deafness. Int J Pediatr Otorhinolaryngol 2013;77(8):1312-1316

16 Wiley S, Jahnke M, Meinzen-Derr J, Choo D. Perceived qualitative benefits of cochlear implants in children with multi-handicaps. Int J Pediatr Otorhinolaryngol 2005;69(6):791-798

17 Edwards LC. Children with cochlear implants and complex needs: a review of outcome research and psychological practice. J Deaf Stud Deaf Educ 2007;12(3):258-268

18 Daneshi A, Hassanzadeh S. Cochlear implantation in prelingually deaf persons with additional disability. J Laryngol Otol 2007; 121(7):635-638

19 Vlahović S, Sindija B. The influence of potentially limiting factors on paediatric outcomes following cochlear implantation. Int $\mathrm{J}$ Pediatr Otorhinolaryngol 2004;68(9):1167-1174 